\title{
Determinants of Unmet Need for Family Planning in Bangladesh: Analysis of Matched Case-Control Survey Data of Bangladesh
}

\author{
Kakoli Khatun $^{1 *}$ and Taslim Sazzad Mallick ${ }^{2}$ \\ ${ }^{I}$ Department of Statistics, Bangabandhu Sheikh Mujibur Rahman Science and Technology University, Gopalganj, \\ Bangladesh \\ ${ }^{2}$ Department of Statistics, University of Dhaka, Dhaka-1000, Bangladesh
}

(Received : 2 February 2020; Accepted : 4 October 2020)

\begin{abstract}
Unmet need for family planning (FP) is responsible for lowering contraceptive rate which elevate unwanted pregnancy that have adverse effects on maternal and child health. This study uses Bangladesh Demographic Health Survey, 2014 data in order to identify the factors that are associated with unmet need for FP in Bangladesh. Since the survey is observational, a case-control data has been used matched by age and education of the respondents and the analysis was carried out by using a conditional logistic regression. Unmet need for FP was found to be higher in the rural area, among Muslims, among women who were not exposed to media or not member of any NGO, among couples having no sons.
\end{abstract}

Keywords: Unmet need, matching, case-control study, conditional logistic regression, odds ratio

\section{Introduction}

Unwanted Pregnancy may result in abortion or unwanted live birth. Abortion may cause long term adverse effects on maternal health including infertility, life-threatening complications and maternal death ${ }^{1}$. On the other hand, unwanted live births not only contribute in increasing the fertility rate of a country but also they are less likely to receive all recommended vaccinations; to be stunted and to die during neonatal, post-neonatal and early childhood periods ${ }^{2}$. Unwanted pregnancy occurs due to non-use of contraceptive services, failure contraceptive and rape ${ }^{1}$. The non-use of contraceptive services when a woman wants to postpone or stop child bearing, is well known as unmet need for family planning (FP). To achieve the sustainable development goal (SDG) regarding total fertility rate (TFR), Bangladesh needs to reduce TFR 2.3 to 2.0 by 2030 . Currently, the total unwanted fertility rate is 0.7 and rate of induced abortion was estimated as 29 per 1000 women aged $15-49$ in $2014^{3,4}$. Therefore, TFR would be 1.6 ( 30 percent lower than the current TFR) if these unwanted births would have been avoided ${ }^{3}$. Moreover, the contraceptive prevalence rate (CPR) is $62.4 \%$ in 2014 , which has been increased by $17.8 \%$ since 1994. On the other hand, unmet need has been decreased ${ }^{3}$ to $12 \%$ in 2014 from $21.6 \%$ in 1994 . That is, the current CPR would have been $74.4 \%$ if this unmet need were avoided. In order to reduce fertility rate, increase CPR and to improve maternal and child health in Bangladesh, it is essential to reduce unmet need to a great extent. To achieve this, it is essential to find out the potential determinants associated with unmet need.

It is not always meant that unmet need is caused only for less availability of services. It may also mean that women who have lacking of information regarding the availability of the FP services, not have much inspiration or confidence and they are not empowered enough to take decision about FP can be considered as some causes ${ }^{5}$. Moreover, fear of side effects, waiting for a change in reproductive cycle and gender subordination are also responsible for unmet need ${ }^{6}$. The existing problem regarding FP can be solved as a way to improve communication between spouse about contraception, childbearing and related issues and to change men's attitude about the desirability to have child ${ }^{7}$. It is considered that husband's endorsement of contraception and couple's discussion about family planning are two major factors to be accounted when thinking of interventions to reduce unmet need for family planning ${ }^{8}$. Media especially radio have a significant effect on contraceptive use in Bangladesh ${ }^{9}$.

The researches carried out so far focusing on unmet need for FP and its determinants used observational studies. In an observational study, regression analysis is an effective tool to estimate effects of covariates after adjusting effects of possible confounders. However, when the comparison groups differ too much in terms of the background characteristics of the respondents, regression analysis may fail to estimate true effects of the covariates under consideration. In observational studies, as there is no control over the background characteristics of respondents, matching has been found effective in balancing certain observed covariates, so that the groups are comparable with respect to the factors under consideration ${ }^{10}$. In the present research, Bangladesh Demographic Health Survey (BDHS), 2014 has been used to identify the factors that have significant association with unmet need for FP. Since BDHS, 2014 was an observational study, a matched data has been extracted and a conditional logistic regression model has been fitted to identify the true factors responsible for unmet need for FP.

\section{Data and Method}

BDHS, 2014 was a nationally representative survey based on two-stage stratified cluster sampling procedure. The first stage of this survey selected 600 enumeration areas (EAs) with probability proportional to EA size. A sample of 30 households was selected from each EAs by using a systematic sampling at the second stage. A total of 18,000 
residential households were selected for the interview and BDHS successfully interviewed 17,863 ever married women. Here, the factors considered to be associated with unmet need for FP are region, place of residence, education of women, religion, wealth index, age of women, education gap between husband and wife, exposure to mass media, women empowerment, number of sons and number of daughters. Note that a woman is considered to be empowered if at least one of her decisions about own health care, major household purchases, child's health care and visits to their family or relatives was accepted by her family. After removing the missing values, a total of 12,131 women were selected for this study.

The response variable used here is the need for contraception which is categorized as unmet need and met need. It has already been mentioned earlier that the non-use of contraceptive services when a woman wants to postpone or stop child bearing, is known as unmet need for family planning (FP). It should be noted that when fecund women not using contraception wish to postpone the next birth is unmet need for spacing and when fecund women without contraception when wish to stop child bearing altogether is unmet need for limiting. Unmet need for FP is the combination of the above two. On the other hand, women who are using contraceptives are said to have met need ${ }^{11}$.

It was observed from the sample that $14.3 \%$ of our sample observation had an unmet need for FP while rest of them had a met need for FP. A major portion of the women were from rural areas $(65.3 \%)$ and about $90 \%$ were Muslim. It is also observed from the sample that $30.7 \%$ women were below 20 years old, $21.1 \%$ women had no education, $37.1 \%$ were poor and about $52 \%$ had no education gap with their husband. It is surprising that majority of the women had no media exposure $(78.6 \%)$ and were not aware of community clinics (70\%). In the selected sample, couples without any daughter $(30.4 \%)$ was found to be higher than the couple without any son $(24.8 \%)$.

\section{Statistical Analysis}

Bivariate analyses using chi-square tests have been performed in order to estimate the unadjusted effects of the selected factors on unmet need for FP. A logistic regression model was then fitted as an effort to estimate the adjusted effects. Both the bivariate and binary regression analyses have been used for the full dataset consisting of $n=$ 12,131 women. A matched case-control data of $n_{M}=$ 3,546 women was then selected from the full dataset and a conditional logistic regression model was fitted to the data. Conditional logistic regression model under matched casecontrol study design is briefly outlined below. The findings are illustrated in the result section.

\section{Logistic regression model for Matched case-control study}

For a case-control design with matched pairs, a case is matched with a control based on certain matching variables. In the present setup, a case is a woman who has unmet need for FP while a control is the one having met need. Suppose that $\left(Y_{i 1}, Y_{i 2}\right)$ denote binary response the $i$-th pair of observations, $i=1,2, \cdots, n_{M}$ with $Y_{i t}=1$ indicating the $i$ th respondent having unmet need for FP in the $t$-th $(t=$ $1,2)$ case/control group. Then the logit model is defined as

$$
\begin{aligned}
\operatorname{logit}\left[P\left(Y_{i t}=1\right)\right] & \\
& =\log \left[\frac{Y_{i t}=1}{Y_{i t}=0}\right] \\
& =\alpha_{j}+\beta_{1} x_{i t 1}+\cdots+\beta_{j} x_{i t j}+\cdots \\
& +\beta_{i t p} x_{i t p}
\end{aligned}
$$

where $x_{i t j}$ denotes the value of $j$-th covariate and $\beta_{j}$ is the corresponding log-odds ratio. Note that the subject specific intercept parameter $\alpha_{j}$ 's are the nuisance parameters that we do not want to estimate. Conditional maximum likelihood estimation approach is used to estimate the effects of covariates considered in the model.

Hypothesis to be tested here

$H_{0}: \beta_{j}=0$, equivalently $H_{0}: e^{\beta_{j}}=1$,

where $e^{\beta_{j}}$ is the odds ratio (OR).

Test statistic is given by,

$W=\frac{e^{\widehat{\beta}_{j}}-1}{\sqrt{e^{2 \widehat{\beta}_{j}}}} \sim N(0,1)$,

and the $95 \%$ confidence interval (CI) for OR is

$$
\widehat{O R} \pm z_{1-\alpha / 2} \sqrt{e^{2 \widehat{\beta}_{j}}} S E\left(\hat{\beta}_{j}\right)
$$

\section{Results and Discussion}

\section{Bivariate Analysis}

We started the analysis by estimating unadjusted effects of the factors covariates described in Section 2. The results obtained from the bivariate analysis are reported in Table 1. Almost all the selected covariates were found to be significantly associated with unmet need for FP except the variable exposure to media (Chi-square test based $p$-values $<0.05$ ). Unmet need for FP varies between $8.2 \%$ to $23.7 \%$ among divisions, lowest being observed in Khulna while the highest was in Chittagong and Sylhet divisions. The rate of unmet need for FP was higher in the rural area, it decreases as age of women increases. There was not much variation in rates over education categories, however, those with secondary level of education had higher rate. This rate was higher for the Muslims, and it increases with the increase of wealth status. Women who were not member of NGO had higher rate of unmet need. Empowered women had significantly lower unmet need for FP. Couples having no son or no daughter had significantly higher unmet need, which indicates that couples preferred to have children of both genders. Those who are not exposed to media, have higher rate of unmet need for FP which, however, is not statistically significant. 
Table 1. Percentage distribution of unmet need for FP for several background characteristics.

\begin{tabular}{|c|c|c|c|}
\hline Variables & Category & $\begin{array}{l}\text { Met need } \\
n(\%)\end{array}$ & $\begin{array}{l}\text { Unmet need } \\
n(\%)\end{array}$ \\
\hline \multirow{4}{*}{ Division* } & Chittagong & $1440(76.3)$ & $448(23.7)$ \\
\hline & Khulna & $1612(88.4)$ & $211(11.6)$ \\
\hline & Rajshahi & $1648(91.9)$ & $148(8.2)$ \\
\hline & Rangpur & $1657(90.5)$ & $173(9.5)$ \\
\hline \multirow[t]{2}{*}{ Place of residence* } & Urban & $3728(88.5)$ & $485(11.5)$ \\
\hline & Rural & $6630(83.7)$ & $1288(16.3)$ \\
\hline \multirow{3}{*}{ Age (in years)* } & $<20$ & 1012 (77.6) & $292(22.4)$ \\
\hline & $20-30$ & $4420(85.2)$ & $766(14.8)$ \\
\hline & $>30$ & $4926(87.3)$ & $715(12.0)$ \\
\hline Education level* & Above secondary & $1061(86.1)$ & $172(13.9)$ \\
\hline \multirow[t]{2}{*}{ Religion* } & Non- Muslim & $1106(91.9)$ & $97(8.3)$ \\
\hline & Muslim & $9252(84.7)$ & $1676(15.3)$ \\
\hline \multirow{3}{*}{ Wealth index* } & Poor & $3884(86.5)$ & $608(13.5)$ \\
\hline & Middle & $2094(85.0)$ & $379(15.0)$ \\
\hline & Rich & $4380(84.6)$ & $795(15.4)$ \\
\hline \multirow{3}{*}{ Education gap* } & Wife more educated & $2697(84.7)$ & $486(15.3)$ \\
\hline & No gap & $5389(85.8)$ & $893(14.3)$ \\
\hline & Wife less educated & $2272(85.2)$ & $394(14.8)$ \\
\hline Women Empowerment* & Empowered & $8276(86.5)$ & $1295(13.5)$ \\
\hline \multirow[t]{2}{*}{ Number of sons* } & 0 & $2446(81.4)$ & $559(18.6)$ \\
\hline & $\geq 1$ & $7912(86.7)$ & $1214(13.3)$ \\
\hline \multirow[t]{2}{*}{ Number of daughters* } & 0 & $3106(84.3)$ & $577(15.7)$ \\
\hline & $\geq 1$ & $7252(85.8)$ & $1196(14.2)$ \\
\hline \multirow[t]{2}{*}{ Aware of community clinic* } & No & $3095(85.0)$ & $547(15.0)$ \\
\hline & Yes & $7263(85.6)$ & $1226(14.4)$ \\
\hline
\end{tabular}

$* p$-value $<0.05$

Multivariate analysis: Comparison between results from matched and unmatched data

Since the association measure obtained from an observation study may not reflect the true picture due to lack of control over the background characteristics of respondents, in this study, we have used a matched case-control data extracted from the full BDHS, 2014 dataset in order to estimate the true adjusted effects of several factors on unmet need for FP. Since respondents' age and education level are found to be confounding factors in most of the cases, we match a case (unmet need for FP) with a control (met need for FP) by age and education level. This matching ensures the distributions of age and education level to be the same for both case and control groups. The matched dataset was comprised of $n_{M}=3,546$ respondents of which $50 \%$ had met and the other $50 \%$ had unmet need for family planning. This matched data has been analyzed using a conditional logistic regression model. Note that in a matched data, 
responses in case and control groups are dependent and hence analysis using regular logistic regression model is not appropriate. We further analyze the full data using logistic regression model in order to show the differences in results between matched and unmatched data. Results for both unmatched and matched data are shown in Table 2.

It is observed from the table that the effects of wealth index, media exposure, women empowerment and number of daughters were not the same for matched and unmatched data. To be specific, wealth index, women empowerment and number of daughters were showing significant association with unmet need for FP in the unmatched data, while they were insignificant in the matched data. On the other hand, media exposure was not significant in the unmatched data, but it was found to be significant in the matched data.

Table 2. Adjusted odds ratios (ORs) from matched and unmatched data.

\begin{tabular}{|c|c|c|c|}
\hline Variables & Category & $\begin{array}{l}\text { Matched data } \\
\text { OR }(95 \% \mathrm{CI})\end{array}$ & $\begin{array}{l}\text { Unmatched data } \\
\text { OR }(95 \% \mathrm{CI})\end{array}$ \\
\hline \multirow{4}{*}{ Division } & Chittagong & $1.51(1.17,1.97)^{*}$ & $1.78(1.47,2.16)^{*}$ \\
\hline & Khulna & $0.70(0.53,0.92)^{*}$ & $0.76(0.62,0.94) *$ \\
\hline & Rajshahi & $0.48(0.36,0.65)^{*}$ & $0.51(0.29,0.74)^{*}$ \\
\hline & Rangpur & $0.54(0.41,0.72)^{*}$ & $0.64(0.41,0.64) *$ \\
\hline \multirow[t]{2}{*}{ Place of residence } & Urban & 1.00 & 1.00 \\
\hline & Rural & $1.54(1.31,1.83)^{*}$ & $1.68(1.48,1.90)^{*}$ \\
\hline \multirow[t]{2}{*}{ Age } & $<20$ years & - & 1.00 \\
\hline & 20-30 years & - & $0.75(0.63,0.89) *$ \\
\hline \multirow{2}{*}{ Education level } & Secondary & - & $1.01(0.85,1.20)$ \\
\hline & Above secondary & - & $0.97(0.77,1.25)$ \\
\hline \multirow[t]{2}{*}{ Religion } & Non-Muslim & 1.00 & 1.00 \\
\hline & Muslim & $2.08(1.60,2.74)^{*}$ & $1.89(1.52,2.36) *$ \\
\hline \multirow[t]{3}{*}{ Wealth index } & Poor & 1.00 & 1.00 \\
\hline & Middle & $1.22(0.92,1.37)$ & $1.12(0.97,1.30)$ \\
\hline & Rich & $1.15(0.93,1.40)$ & $1.25(1.08,1.46)^{*}$ \\
\hline \multirow[t]{2}{*}{ Education gap } & Husband less educated & 1.00 & 1.00 \\
\hline & No gap & $0.92(0.75,1.09)$ & $0.94(0.83,1.08)$ \\
\hline \multirow[t]{2}{*}{ Women empowerment } & Not empowered & 1.00 & 1.00 \\
\hline & Empowered & $0.83(0.67,1.00)$ & $0.81(0.70,0.94)^{*}$ \\
\hline \multirow[t]{2}{*}{ Number of sons } & 0 & 1.00 & 1.00 \\
\hline & $\geq$ & $0.73(0.62,0.87)^{*}$ & $0.69(0.57,0.83)^{*}$ \\
\hline \multirow[t]{2}{*}{ Number of daughters } & 0 & 1.00 & 1.00 \\
\hline & $\geq$ & $0.85(0.70,1.01)$ & $0.83(0.72,0.96)^{*}$ \\
\hline \multirow[t]{2}{*}{ Aware of community clinic } & Unaware & 1.00 & 1.00 \\
\hline & Aware & $0.95(0.80,1.10)$ & $0.95(0.80,1.12)$ \\
\hline
\end{tabular}

$* p$-value $<0.05$ 
The adjusted effects obtained from the matched data show that unmet need for FP in Chittagong and Sylhet divisions were significantly higher, while in Khulna, Rajshahi and Rangpur it was significantly lower than that in Dhaka division. The odds of unmet need for FP was 54\% higher in the rural area and for the Muslims this odds was almost double. Women having media exposure and NGO membership had lower odds of unmet need for FP; these odds were $21 \%$ and $38 \%$ lower than the reference groups, respectively.

An interesting finding is that a couple having no son had $34 \%$ significantly higher odds of unmet need for FP. This indicates significant role of son preference on the unmet need for FP. It should be noted that son preference is common in South Asia and in many other developing countries due to the fact that sons provide better support as compared to daughters when their parents become old ${ }^{12-19}$.

\section{Conclusion}

In order to achieve the target of SDG goal regarding fertility and to improve maternal and child health in Bangladesh, it is essential for the policy makers to know about the factors that affect unmet need for FP. This study attempts to correctly identify the factors associated with unmet need for FP using a matched case-control BDHS, 2014 data. It was found that unmet need for FP was significantly higher in rural area, among Muslims, among those who were not exposed to media, who were not member of any NGO. This study also reveals an interesting new fact that unmet need for FP was significantly higher among the couples having no sons. It has been shown that the findings based on unmatched data varied when a matched data had been used. Since this study used a matched case-control data based on age and education level, we expect that the results based on this data depict the true association between unmet need for FP and the selected covariates. Based on the findings of this study, it is suggested to strengthen family planning program in the rural area, among Muslims. It may also be suggested to target couples those have children without any son and educate them about proper use of contraceptives if they wish to postpone the next birth or stop childbearing.

\section{References}

1. Klima, C. S. 1998. Unintended pregnancy, consequences and solutions for a worldwide problem. Journal of Midwifery and Women. 43 (6), 483-491.

2. Singh, A., Chalsani, S., Koenig, M. A. and Mahapatra, B. 2012. The consequences of unintended births for maternal and child health in India. Population Studies, 66(3): 223-239.

3. Bangladesh Demographic and Health Survey (BDHS), 2014. NIPORT, Dhaka, Bangladesh; Mitra and Associates, Dhaka/Bangladesh.
4. Fact Sheet, 2012. Menstrual Regulation and Induced Abortion in Bangladesh. Guttmacher Institute.

5. Pradhan, J. and Dwivedi, R., 2015. Why unmet need for family planning remains high in Bangladesh: A Community Level Analysis. Journal of Women's Health Care, 290 (4), 14.

6. Barrios, A. D., Rodas, M. D. and Yinger, N. V. 1997. Unmet need for family planning in a peri-urban community of Guatemala City. International Center for Research on Women, 23 (5): 1-10.

7. Bongaarts, J. and Bruce, J. 1995. The causes of unmet need for contraception and the social content of services. Studies in Family Planning, 26: 57-75.

8. Ajong, A. B., Njotang, P.N., Yakum, M.N., Essi, M. J., Essiben, M., Eko, F. E., Kenfack, B. and Mbu, E. R. 2016. Determinants of unmet need for family planning among women in Urban Cameroon: A cross sectional survey in the Biyem-Assi Health District, Yaounde. BMC Women's Health, 16 (4): 1-8.

9. Islam, M. M. and Hasan, A. H. M. S. 2000. Mass media exposure and its impact on family planning in Bangladesh. Journal of Biosocial Science, 32: 513-526.

10. Rosenbaum, P.R. 2009. Design of Observational Studies, Springer.

11. Bradley, S. E., Croft, T. N., Fishel, J. D., Westoff, C. F. 2012. Revising unmet need for family planning. Calverton Maryland ICF International MEASURE DHS.

12. Bairagi, R. and R.L. Langsten, Sex preference for children and its implications for fertility in rural Bangladesh. 1986. Studies in family planning, 17(6): 302-307.

13. Nag, M., Sex preference in Bangladesh India and Pakistan and its effect on fertility. 1991. Demography India, 20(2): 163-85.

14. Khan, M.A. and P.A. Khanum, Influence of son preference on contraceptive use in Bangladesh. 2000. Asia-Pacific Population Journal, 15(3): 43-56.

15. Arnold, F., Measuring the effect of sex preference on fertility: the case of Korea. 1985. Demography, 22(2): 280288.

16. Bairagi, R., Effects of sex preference on contraceptive use, abortion and fertility in Matlab, Bangladesh. 2001. International Family Planning Perspectives, 137-143.

17. Yount, K.M., R. Langsten, and K. Hill, The effect of gender preference on contraceptive use and fertility in rural Egypt. Studies in family planning. 2000. 31(4): 290-300.

18. Chowdhury, M.K. and R. Bairagi, Son preference and fertility in Bangladesh. 1990. Population and Development Review, 749-757.

19. Amin, R. and A.G. Mariam, Son preference in Bangladesh: an emerging barrier to fertility regulation. 1987. Journal of Biosocial Science, 19(2), 221-228. 
